\title{
Childhood size is more strongly related than size at birth to glucose and insulin levels in 10-11-year-old children
}

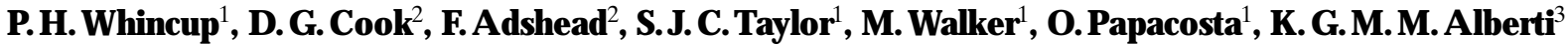 \\ ${ }^{1}$ Cardiovascular Research Unit, Department of Primary Care and Population Sciences, Royal Free Hospital School of Medicine, \\ London, UK \\ ${ }^{2}$ Department of Public Health Sciences, St. George's Hospital Medical School, London, UK \\ ${ }^{3}$ Department of Medicine, University of Newcastle upon Tyne, Newcastle, UK
}

Summary In adults low birthweight and thinness at birth are associated with increased risk of glucose intolerance and non-insulin-dependent diabetes mellitus. We have examined the relations between size at birth (birthweight, thinness at birth) and levels of plasma glucose and serum insulin in children, and compared them with the effects of childhood size. We performed a school-based survey of 10-11-yearold British children (response rate $64 \%$ ) with measurements made after an overnight fast. One group of children $(n=591)$ was studied fasting while the other $(n=547)$ was studied 30 min after a standard oral glucose load $(1.75 \mathrm{~g} / \mathrm{kg})$. Serum insulin was measured by a highly specific ELISA method. Birthweight was assessed by maternal recall and thinness at birth using birth records. Neither fasting nor postload glucose levels showed any consistent relationship with birthweight or ponderal index at birth. After adjustment for childhood height and ponderal index, both fasting and post-load insulin levels fell with increasing birthweight. For each $\mathrm{kg}$ increase in birthweight, fasting insulin fell by $16.9 \%$ (95\% confidence limits $7.1-25.8 \%, p=0.001)$ and post-load insulin by $11.6 \%$ (95\% confidence limits $3.5-19.1 \%$, $p=0.007)$. However, the proportional change in insulin level for a 1 SD increase in childhood ponderal index was much greater than that for birthweight $(27.2 \%$ and $-8.8 \%$, respectively, for fasting insulin). We conclude that low birthweight is not related to glucose intolerance at 10-11 years, but may be related to the early development of insulin resistance. However, in contemporary children obesity is a stronger determinant of insulin level and insulin resistance than size at birth. [Diabetologia (1997) 40: 319-326]

Keywords Birth weight, ponderal index, glucose, insulin, children.
Events occurring before birth and in infancy may influence the risk of adult cardiovascular disease [1]. Associations between small size at birth and increased risk of adult cardiovascular mortality have been described in historical cohort studies [2, 3]. Although associations between size at birth and several

Received: 26 August 1996 and in revised form: 19November 1996

Corresponding author: Dr. P.H. Whincup, Cardiovascular Research Unit, Department of Primary Care and Population Sciences, Royal Free Hospital School of Medicine, London NW3 2PF, UK

A bbreviations: NIDDM, Non-insulin-dependent diabetes mellitus; HOMA, Homeostasis Model Assessment. adult cardiovascular risk factors have been reported [1], those between size at birth, glucose intolerance and non-insulin-dependent diabetes mellitus (NIDDM) are among the most consistently described [4]. Low birthweight has been related to increased risk of glucose intolerance and NIDDM in middleaged British subjects in Hertfordshire [5] and Preston [6] and in a cohort of Swedish men [7]. Relations between birthweight and glucose intolerance in young adults have been reported in widely differing populations [8-10], including pregnant women [11]. More recently it has been suggested that thinness at birth, denoted by a low ponderal index at birth (birthweight/birth length ${ }^{3}$ ) might be specifically related to risk of glucose intolerance $[6,7]$. Whether the basis of the association between small size at birth and 
impaired glucose tolerance rests on a reduced pancreatic beta-cell mass and consequent insulin hyposecretion in small babies [5, 6], or a relationship with insulin resistance $[7,12,13]$ remains uncertain, although recent evidence suggests that small size at birth interacts with later obesity to produce the most marked degree of insulin resistance [7].

Most of the studies relating size at birth and glucose intolerance are based on adults, often born in the first half of the twentieth century [5-7, 12, 13], when perinatal and infant mortality rates were much higher than those prevalent today. However, the relevance of these associations to contemporary children is less clear. In a study of 2507 -year-old British children, ponderal index at birth, but not birthweight, was reported to be related to post-load glucose level; neither measure was related to insulin level [14]. Conversely, in 2014 -year-old Indian children, birthweight was inversely related to post-load glucose and insulin levels [15]. In a study of 610 Jamaican children aged 6-10 years, length at birth was inversely related to glycated haemoglobin level, but birthweight and ponderal index were not [16]. In an attempt to resolve these inconsistencies, we have studied the relations between size at birth, serum insulin and plasma glucose in a larger population-based study of 10-11year-old British children, half of whom were studied fasting and half after a glucose load.

\section{Subjects and methods}

Sampling procedures. Details of this survey of cardiovascular risk factors in children have been published elsewhere [17]. The study took place in ten towns in England and Wales - five with exceptionally low adult cardiovascular mortality rates (Esher, Leatherhead, Bath, Chelmsford, Tunbridge Wells) and five with exceptionally high adult cardiovascular mortality rates (Wigan, Port Talbot, Burnley, Rochdale, Rhondda). In each town, a stratified random sample of ten Junior Schools was selected; 22 children aged 10-11 years in each school were invited to provide a blood sample for measurement of blood glucose, insulin and blood lipids.

Survey procedures. Ethical approval was obtained from all relevant local research ethics committees and informed written parental consent was sought for all participants. All measurement surveys ( 1 week per town, alternating between high and low mortality towns) were carried out between April and November 1994. Consenting children were sent a card asking them not to eat or drink anything other than water before attending school on the morning of the survey and were questioned about compliance with these instructions at the time of measurement. All physical measurements were made by one of two pairs of trained field nurses and the blood sample by the team doctor.

Blood sampling. Local anaesthetic skin cream (EMLA, Astra Pharmaceuticals Ltd, King's Langley, Herts, UK) was applied at least $45 \mathrm{~min}$ before blood sampling. Samples from the first half of the children assessed each day were collected fasting (between 09.30 and 10.45 hours in $96 \%$ of cases). Samples from the second half were taken 30 min after ingestion of a standard $(1.75 \mathrm{~g} / \mathrm{kg})$ oral glucose load (Lucozade; Smith Kline Beecham PLC, Brentford, Middlesex, UK) (between 10.20 and 11.30 hours in $94 \%$ of cases). All children were offered breakfast after the procedure. The 30-min interval was chosen in preference to the 120-min interval because (a) inverse relationships between size at birth and post-load glucose level in adults were observed at $30 \mathrm{~min}$ as well as at $120 \mathrm{~min}$ in earlier studies and (b) the early peak of insulin action is particularly important in determining glucose tolerance [18]. Blood samples were centrifuged, separated and frozen at $-20^{\circ} \mathrm{C}$ within $4 \mathrm{~h}$ of collection. All analyses were carried out in central laboratories. Plasma glucose (fluoride oxalate sample) was analysed using the Glucose-Technicon Axon system, (Bayer, Tarrytown, NY, USA) (method SM4-2143F90). Serum insulin was measured using an ELISA method which does not cross-react with proinsulin [19] at the Department of Medicine, University of Newcastle upon Tyne.

Physical measurements. Patients were dressed in light clothing, without shoes. Height was measured to the last complete millimetre using a portable stadiometer (CMS Ltd, Camden, UK). Weight was measured to the last complete $0.1 \mathrm{~kg}$ using a digital electronic weighing scale (Soehnle Ltd, Murrhardt, Germany). Ethnic group was assessed on the basis of the child's appearance. Ponderal index (weight $/$ height $^{3}$ ) is used as an index of weight-for-height in childhood since (unlike body mass index) it is independent both of height and age in this study population.

Parental questionnaire and birth record data. A questionnaire with reply-paid postage was forwarded to parents on the day of the survey. Parents were asked to provide information on the child's birthweight and on their own occupation(s), which was (were) coded in accordance with the Registrar General's 1980 social class coding manual, and their present and previous smoking habits. They were also asked to give permission for the collection of information from birth records, including measures of size at birth. This information was sought in all cases where parents gave permission and where children were born at hospitals in or close to the town where they were surveyed. Birthweight data in this report is based on maternal recall, except in 42 cases where birthweight was available from the birth records but could not be recalled by the mother. Where birthweight data was available from both sources $(n=551)$, there was exceptionally close overall agreement (mean difference $0.5 \mathrm{~g}, \mathrm{SD} 0.98 \mathrm{~g}, \mathrm{r}=0.98$ ). The assessment of length at birth (crown-heel) and thinness at birth (birthweight/birth length ${ }^{3}$ as in earlier reports $\left.[6,12]\right)$ are based on length at birth and birthweight data from the birth records.

\section{Statistical analysis}

All analyses have been carried out using the SAS statistical package (SAS Institute Inc, Cary, N.C., USA). The distributions of fasting and post-load glucose were reasonably normally distributed, while serum insulin levels were markedly skewed. Serum insulin levels were therefore normalized by log-transformation and geometric mean values have been used throughout. Relationships between size at birth, childhood size and levels of glucose and insulin were examined in fifths and, where appropriate, using corresponding linear regression models. Where insulin was an outcome variable in linear regression analyses, it was fitted as log [insulin] and the regression coefficients were exponentiated to obtain estimates of proportional change in insulin level per unit change in 
Table 1. Characteristics of survey participants

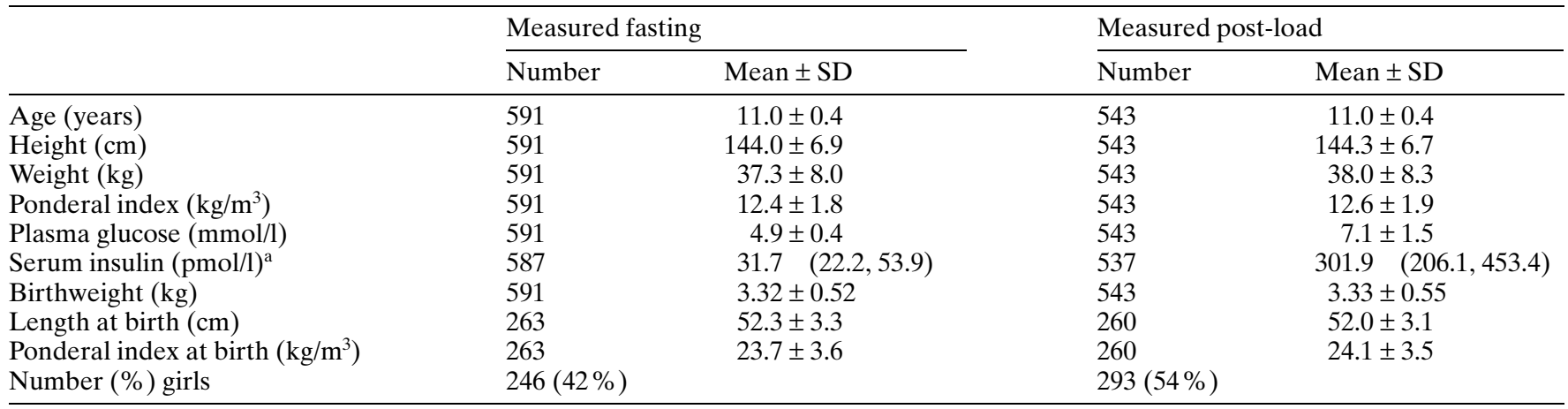

Data are mean \pm SD

${ }^{a}$ Geometric mean (interquartile range)

birthweight or ponderal index at birth. All the main analyses have included adjustment for age (fifths), sex (two levels), town (ten levels) and time of day of blood sampling (in 15min intervals); post-load data are adjusted for variation in the interval between glucose load and venepuncture (min). Adjustments for childhood height and ponderal index have been carried out with these variables fitted in equal fifths. To study the relative effects of birthweight and childhood ponderal index on insulin level, the proportional changes in insulin level for a $1 \mathrm{SD}$ increase in each of the two other variables have been compared. Calculated estimates of pancreatic beta-cell function (insulin/[glucose-3.5]) and insulin resistance (insulin $\times$ glucose) $/ 22.5$ ) have been determined from fasting values in accordance with the 'homeostasis model assessment' (HOMA) model [20].

\section{Results}

Of 2172 children invited for measurement and blood sampling, 1398 children (64\% response rate) underwent both physical measurements and blood glucose sampling; 709 children were studied fasting and 689 after a glucose load. All but four of the fasting children and all but six of the children measured postload had insulin measurements taken.

Fasting studies. Among the children measured fasting, $26(3.7 \%)$ children who reported eating breakfast were excluded. Of the remaining 683 children, information on birthweight (either from parental questionnaire or from birth records) was available for 591 children and information on ponderal index at birth (from birth record data on birthweight and birth length) for 263 children. Between 09.30 and 10.45 hours, mean fasting plasma glucose fell by $0.05 \mathrm{mmol} / \mathrm{l}(\mathrm{p}=0.16)$ and geometric mean fasting insulin fell by $10.6 \mathrm{pmol} / \mathrm{l}(\mathrm{p}=0.02)$. Adjustment for these effects was made in analysis, although it had no important effect on the results.

Post-load studies. Among the children measured after a glucose load, 20 (2.9\%) children were excluded because they were unable to drink the appropriate glucose load and $36(5.2 \%)$ because their blood was sampled more than $3 \mathrm{~min}(10 \%)$ on either side of $30 \mathrm{~min}$. Among the remaining 633 children, information on birthweight was available for 543 and information on ponderal index at birth for 260 subjects. Between 10.20 and 11.30 hours, post-load plasma glucose rose by $0.76 \mathrm{mmol} / \mathrm{l}(\mathrm{p}=0.006)$ and geometric mean insulin level rose by $58.9 \mathrm{pmol} / \mathrm{l}(\mathrm{p}=0.38)$. Mean blood glucose measurements were slightly higher at 30 and $31 \mathrm{~min}$ after a glucose load than at 27-29 and 32-33 min (test for heterogeneity, $p=0.08$ ) but insulin levels were little affected by glucose load-sampling interval (test for heterogeneity, $p=0.32$ ). Time of measurement and glucose load interval were adjusted for in analysis, although again the results were little affected.

The characteristics of the participating children measured fasting and after a glucose load are summarized in Table 1. As expected, glucose and insulin levels were considerably higher in subjects measured after a glucose load. The proportion of girls was somewhat higher in the post-load group than the fasting group. However, mean age, childhood size and birth measurements were very similar in the two groups. Both fasting and post-load geometric mean insulin levels (but not glucose levels) were slightly higher in girls; all subsequent analyses have been adjusted for sex. Almost all the children studied were white $(95.0 \%)$. There was no consistent difference in glucose or insulin levels between high and low mortality towns.

Childhood size, glucose and insulin levels at 1011 years. Regression coefficients summarizing the relations between current body size, glucose and insulin are presented in Table 2. Regression coefficients for glucose represent absolute change per unit change in body size, while those for insulin represent proportional (\%) change. Height showed no consistent relation with fasting glucose, post-load glucose or postload insulin. However, it showed a strong positive relation with fasting insulin level. Ponderal index in childhood showed strong positive relations with 
Table 2. Size in childhood and size at birth: relations with glucose and insulin levels

\begin{tabular}{|c|c|c|c|c|c|c|c|c|c|c|c|c|}
\hline & \multicolumn{6}{|c|}{ Plasma glucose $(\mathrm{mmol} / \mathrm{l})$} & \multicolumn{6}{|c|}{ Serum insulin $(\mathrm{pmol} / \mathrm{l})$} \\
\hline & \multicolumn{3}{|l|}{ Fasting } & \multicolumn{3}{|l|}{ Post load } & \multicolumn{3}{|l|}{ Fasting } & \multicolumn{3}{|l|}{ Post load } \\
\hline & $\begin{array}{l}\text { Regression } \\
\text { coefficient }\end{array}$ & $95 \% \mathrm{CI}$ & $\mathrm{p}$ value & $\begin{array}{l}\text { Regression } \\
\text { coefficient }\end{array}$ & $95 \% \mathrm{CI}$ & $p$ value & $\begin{array}{l}\text { Propor- } \\
\text { tional (\%) } \\
\text { change }\end{array}$ & $95 \% \mathrm{CI}$ & $p$ value & $\begin{array}{l}\text { Propor- } \\
\text { tional (\%) } \\
\text { change }\end{array}$ & $95 \% \mathrm{CI}$ & $\mathrm{p}$ value \\
\hline Age (years) & 0.001 & $\begin{array}{l}(-0.090 \\
0.092)\end{array}$ & 0.99 & -0.311 & $\begin{array}{l}(-0.735 \\
0.113)\end{array}$ & 0.15 & 8.5 & $\begin{array}{l}(-10.8 \\
32.2)\end{array}$ & 0.40 & 14.0 & $(-3.7,35.0)$ & 0.12 \\
\hline Size in childh & ood & & & & & & & & & & & \\
\hline Height $(\mathrm{cm})$ & 0.003 & $\begin{array}{l}(-0.001 \\
0.007)\end{array}$ & 0.11 & -0.019 & $\begin{array}{l}(-0.040 \\
0.002)\end{array}$ & 0.07 & 2.8 & $(1.8,3.8)$ & $<0.0001$ & 1.9 & $(1.1,2.7)$ & $<0.0001$ \\
\hline $\begin{array}{l}\text { Ponderal in- } \\
\operatorname{dex}\left(\mathrm{kg} / \mathrm{m}^{3}\right)\end{array}$ & 0.025 & $\begin{array}{l}(0.009 \\
0.041)\end{array}$ & 0.002 & -0.032 & $\begin{array}{l}(-0.102 \\
0.038)\end{array}$ & 0.37 & 15.1 & $(11.5,18.8)$ & $<0.0001$ & 11.5 & $(8.7,14.4)$ & $<0.0001$ \\
\hline $\begin{array}{l}\text { Size at birth } \\
\text { Birthweight } \\
(\mathrm{kg})\end{array}$ & 0.006 & $\begin{array}{l}(-0.048 \\
0.060)\end{array}$ & 0.83 & 0.022 & $\begin{array}{l}(-0.218 \\
0.262)\end{array}$ & 0.86 & -4.7 & $(-15.3,7.2)$ & 0.41 & -4.6 & $(-13.0,4.6)$ & 0.31 \\
\hline $\begin{array}{l}\text { with adjust- } \\
\text { ment for } \\
\text { childhood } \\
\text { size }\end{array}$ & -0.021 & $\begin{array}{l}(-0.077 \\
0.035)\end{array}$ & 0.45 & 0.115 & $\begin{array}{l}(-0.131 \\
0.355)\end{array}$ & 0.35 & -16.9 & $\begin{array}{l}(-25.8 \\
-7.1)\end{array}$ & 0.001 & -11.6 & $\begin{array}{l}(-19.1 \\
-3.5)\end{array}$ & 0.007 \\
\hline $\begin{array}{l}\text { Ponderal in- } \\
\operatorname{dex}\left(\mathrm{kg} / \mathrm{m}^{3}\right)\end{array}$ & -0.004 & $\begin{array}{l}(-0.017 \\
0.009)\end{array}$ & 0.55 & -0.002 & $\begin{array}{l}(-0.064, \\
0.060)\end{array}$ & 0.94 & -1.3 & $(-4.3,1.6)$ & 0.36 & -0.3 & $(-2.7,2.1)$ & 0.82 \\
\hline $\begin{array}{l}\text { with adjust- } \\
\text { ment for } \\
\text { childhood } \\
\text { size }\end{array}$ & -0.005 & $\begin{array}{l}(-0.019 \\
0.009)\end{array}$ & 0.45 & -0.004 & $\begin{array}{l}(-0.064 \\
0.056)\end{array}$ & 0.89 & -0.6 & $(-3.3,2.2)$ & 0.68 & -0.1 & $(-2.8,1.7)$ & 0.60 \\
\hline
\end{tabular}

Absolute changes in plasma glucose (regression coefficients) and proportional changes in serum insulin are expressed per unit change in each independent variable.

fasting glucose level, and with both fasting and postload insulin levels.

Size at birth and childhood size. Birthweight was strongly related both to childhood height $(r=0.23$, $p<0.0001)$ and to childhood ponderal index $(r=0.11, p=0.0002)$. Ponderal index at birth was only weakly related to childhood height $(r=-0.06$, $p=0.16)$ and to childhood ponderal index $(r=0.05$, $p=0.22$ ). Childhood size is therefore a potentially important confounder of relations between size at birth, glucose and insulin levels - particularly those between birthweight and insulin.

Size at birth and glucose level. The relations between fifths of birthweight, ponderal index at birth and plasma glucose levels are presented in Figure 1, with corresponding linear regression coefficients in Table 2. Neither birthweight, length at birth nor ponderal index at birth showed any consistent relation with glucose level (either fasting or post-load); adjustment for childhood height and ponderal index made no difference to this finding. There was no suggestion of a specific relation between birthweight (or ponderal index at birth) and glucose level in those children who were tallest or who had the highest ponderal index at 10-11 years of age (data not presented).

Size at birth and insulin level. The relations between fifths of birthweight, ponderal index at birth and
All analyses standardized for age, sex, town, time of day and (post-load samples) post-load interval.

Adjustment for childhood size includes height and ponderal index at 10-11 years

serum insulin levels are presented in Figure 1, with corresponding regression coefficients summarizing the relationships between birthweight and insulin levels (expressed as the proportional change in insulin level for a $1 \mathrm{~kg}$ increase in birthweight) in Table 2. Birthweight showed no relation with insulin level in models without adjustment for childhood size. However, after adjustment for childhood height and ponderal index, there was a graded inverse relation between birthweight and insulin level, both fasting and post-load. For each $1 \mathrm{~kg}$ increase in birthweight, fasting insulin level fell by almost $17 \%$. The proportional changes in fasting insulin levels for a $1 \mathrm{~kg}$ increase in birthweight were very similar in girls $(-18.6 \%, 95 \%$ confidence interval -4.0 to $-31.0 \%)$ and boys $(-15.7 \%, 95 \%$ confidence interval -2.6 to $-27.0 \%$ ) (test for sex difference, $p=0.75)$. The relations appeared somewhat stronger in children born at term $(-21.8 \%, 95 \%$ confidence interval -32.4 to -9.6 ) than in those born before 38 weeks $(-14.4,95 \%$ confidence interval -31.3 to $6.8 \%$ ) but this difference was not statistically significant $(p=0.49)$. The relationship between birthweight and post-load insulin was slightly weaker than that for fasting subjects, with a fall in insulin level of about $12 \%$ for a $1 \mathrm{~kg}$ increase in birthweight. All these results were unaffected by standardization for glucose level, by adjustment for parity, maternal smoking in pregnancy, ethnicity and social class, and by the omission of 32 children 

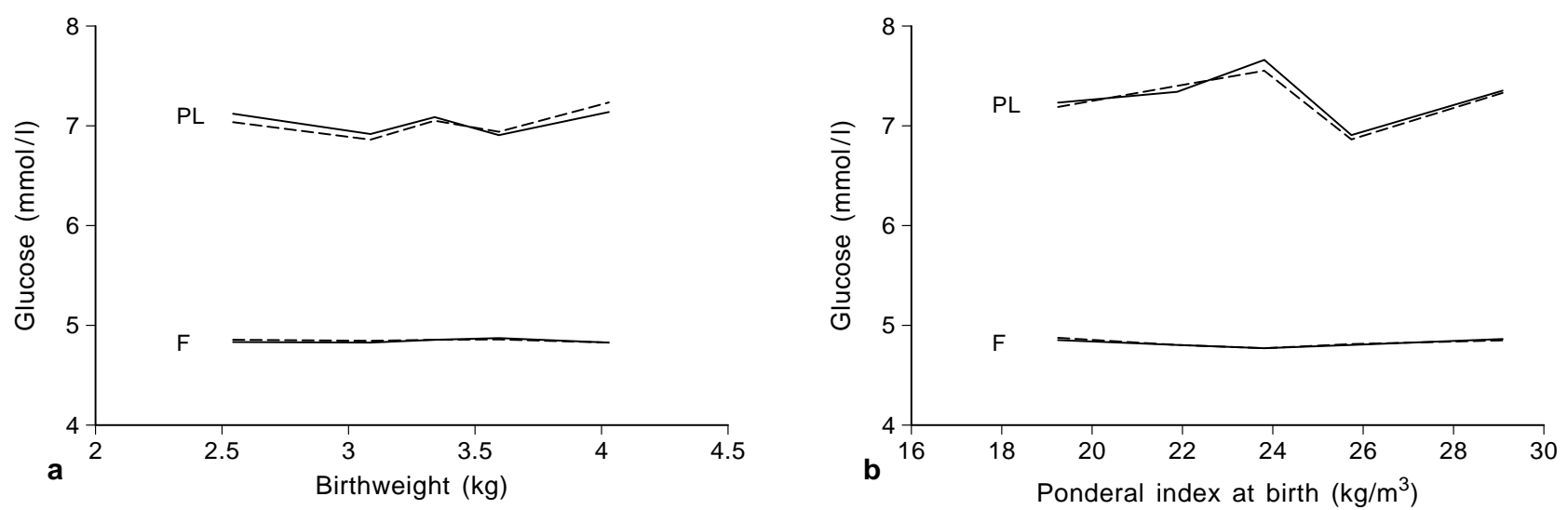

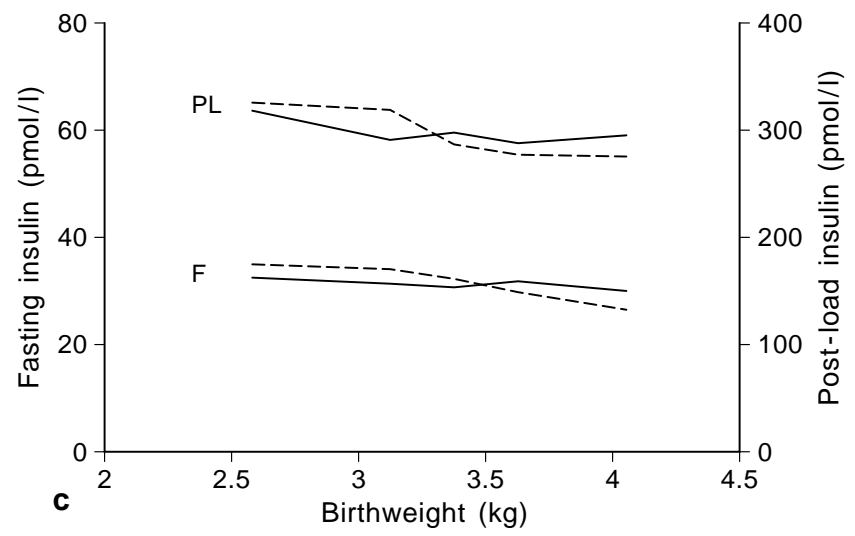

Fig. 1. (a-d) Plasma glucose and serum insulin: relations with birthweight and ponderal index at birth (fifths). (a) birthweight and glucose, (b) ponderal index at birth and glucose, (c) birthweight and insulin, (d) ponderal index at birth and insulin. F, fasting; PL, post-load. Figures are adjusted for age, sex, town, time of day and (for post-load samples) interval between glucose load and venepuncture; dotted lines indicate effect of additional adjustment for childhood height and ponderal index. Insulin values are geometric means

whose mothers reported having a diagnosis of diabetes at any time.

When the relationships between birthweight and insulin were re-examined in the subjects with birth record data, very similar results were found. After adjustment for childhood height and ponderal index, a $1-\mathrm{kg}$ increase in birthweight was associated with a $19.0 \%$ fall in fasting insulin $(p=0.02)$ and a $12.5 \%$ fall in post-load insulin $(p=0.04)$. Birth length showed weak inverse relations with insulin, particularly post-load insulin, after adjustment for childhood height and ponderal index. A 1-cm increase in birth length was associated with a change in fasting insulin of $-2.0 \%$ (95\% confidence interval -5.9 to $2.0 \%$, $p=0.16)$ and a change in post-load insulin of $-2.5 \%$ ( $95 \%$ confidence interval -0.5 to $-4.5, p=0.05$ ). However, ponderal index at birth showed no relation with either fasting or post-load insulin levels either before or after adjustment for childhood size (Table 2).

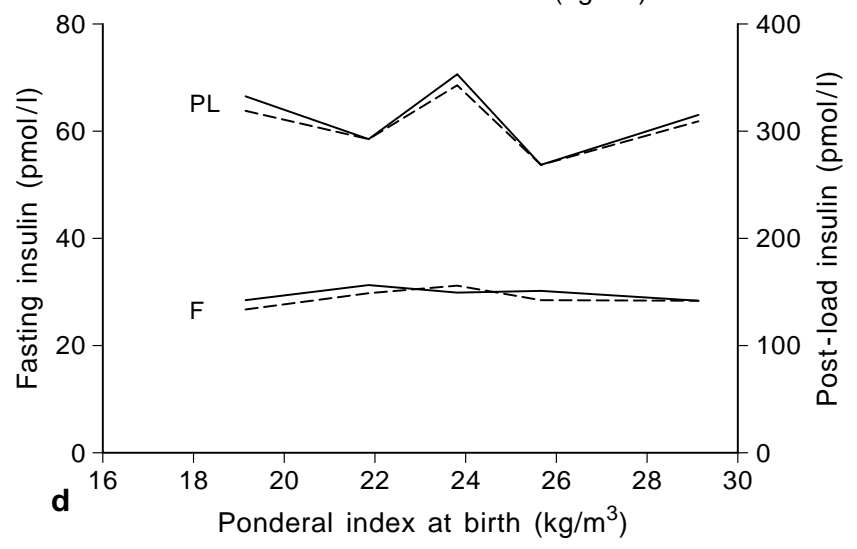

B irthweight, childhood size and insulin level. The possibility that the relationship between birthweight and insulin level depended on height or ponderal index in childhood was examined. The relations between fifths of birthweight, childhood ponderal index and insulin level are presented in Figure 2. In both cases, the highest mean insulin levels were observed in the groups of subjects who were lightest at birth and had the highest ponderal index in childhood. The relationship between birthweight and fasting insulin appeared somewhat stronger in the top fifth of the childhood ponderal index distribution than in the other four groups, but the statistical evidence for difference between them was not strong $(p=0.07)$. The relationship between birthweight and post-load insulin did not appear stronger in the top fifth of the ponderal index distribution than in the other four groups $(p=0.50)$. The replacement of childhood ponderal index by childhood weight produced very similar results. The relations between birthweight and insulin were similar in all fifths of childhood height (data not presented).

To compare the influence of birthweight and childhood ponderal index on insulin levels, the proportional changes in insulin level for a 1 SD difference in each of these measures were calculated. In the case of fasting insulin, a 1 SD increase in birthweight was associated with a change of $-8.8 \%$ (95\% confidence interval -3.7 to $-13.4 \%$ ), compared with a change of $27.2 \%$ (95\% confidence interval 20.7 to $33.8 \%$ ) for a $1 \mathrm{SD}$ increase in childhood ponderal index - a size difference of more than threefold. 

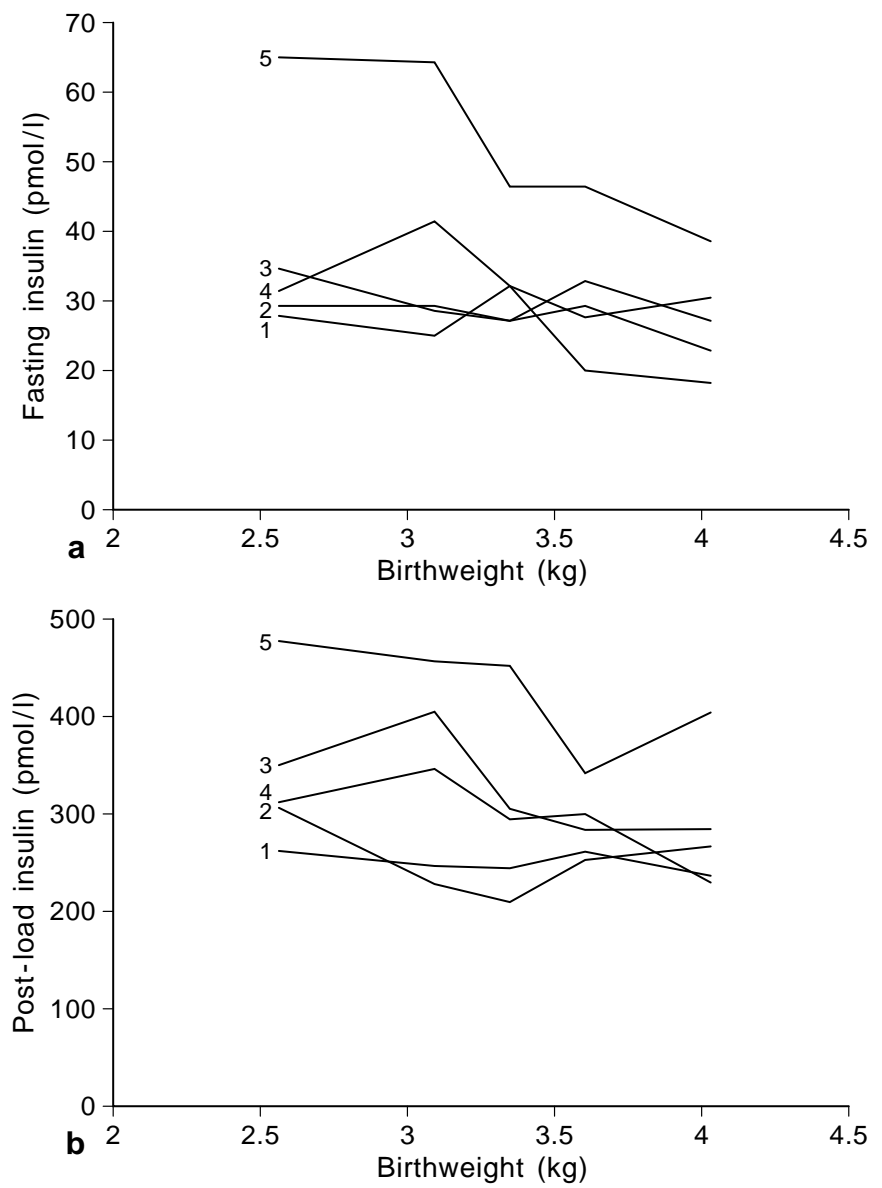

Fig. 2. (a,b) Birthweight (fifths) and insulin concentration, (a) fasting and (b) post-load, by fifths of childhood ponderal index. Figures are adjusted for age, sex, childhood height, town, time of day and (for post-load samples) interval between glucose load and venepuncture. Fifths of childhood ponderal index are shown from 1 (lowest) to 5 (highest). Values $\left(\mathrm{kg} / \mathrm{m}^{3}\right)$ are: $1,8.7$ to $10.9 ; 2,11.0$ to $11.6 ; 3,11.7$ to $12.4 ; 4,12.5$ to 13.6 ; $5,13.7$ to 22.6 . Insulin values are geometric means

Similarly, in the case of post-load insulin, a 1 SD increase in birthweight was associated with a change of $-6.3 \%$ ( $95 \%$ confidence interval -1.9 to $-10.5 \%$ ), compared with a change of $21.9 \%$ (95\% confidence interval 16.5 to $27.4 \%$ ) for a 1 SD increase in childhood ponderal index.

Birthweight, beta-cell function and insulin resistance: HOMA model. After adjustment for childhood height and ponderal index, birthweight was inversely related to the HOMA estimate of insulin resistance (change in insulin resistance [SE] for a $1-\mathrm{kg}$ increase in birthweight $=-1.046[0.303] \mathrm{mmol} \times \mathrm{pmol} / \mathrm{l}$, $p=0.0006$ ) but not to pancreatic beta-cell function (change in beta-cell function for a $1-\mathrm{kg}$ increase in birthweight $=-0.102[0.087] \mathrm{mmol} / \mathrm{pmol}, \mathrm{p}=0.24$ ). Again, however, the relative influence of childhood ponderal index (studied as the effect of a $1 \mathrm{SD}$ increase) on insulin resistance was stronger than that of birthweight, by a factor of 2.6 .

\section{Discussion}

Although studies in adults have consistently demonstrated associations between size at birth and glucose intolerance or prevalence of NIDDM [5-11], the relation between size at birth and post-load glucose measurements in children has been inconsistent. In one British study of 7-year-olds a poorly graded inverse relation between ponderal index at birth (but not birthweight) and 30-min post-load glucose was observed [14]. In a study of 4-year-old Indian children with considerably lower mean birthweight, an inverse association between birthweight and $30 \mathrm{~min}$ postload glucose levels was observed in 201 routine deliveries, but no association was seen in 178 low-birthweight children (less than $2000 \mathrm{~g}$ ) looked after in a special care baby unit [15]. In 610 Jamaican children aged 6-10 years, birth length showed a statistically significant inverse association with glycated haemoglobin level while birthweight and ponderal index at birth did not [16]. The results of the present studies suggest that size at birth is not related to glucose tolerance at the end of the first decade, at least in children in a 'developed' country.

Despite the lack of an association with glucose tolerance, birthweight is inversely related to fasting insulin, a consistent marker of insulin resistance in normoglycaemic subjects [21], and to post-load insulin. However, these associations are dependent on adjustment for childhood size, a procedure which has been criticised on the grounds that childhood size may be an intervening variable in the causal pathway [22]. However, if childhood size were an intervening variable, adjustment might be expected to weaken the association between birthweight and insulin, rather than to strengthen it as observed here. Inverse associations between birthweight and fasting insulin level, although not observed in Hertfordshire, have been reported in two studies of adults [7,9], although not in the two smaller previous studies of children [14, 15]. An inverse association between birthweight and post-load insulin as described in the present study has been more widely described in adults [5-7, 9], and was also reported for 30-min insulin in the earlier study of Indian children [15]. The inverse associations between birthweight, insulin and the HOMA estimates of insulin resistance and beta-cell function would be entirely consistent with a long-term association between size at birth and insulin resistance [7, 12, 13 - although not necessarily with the 'insulin resistance syndrome' [23]. Although birthweight is inversely related to blood pressure as well as to insulin level in this study population [24], it is not related to central obesity, triglyceride and HDL-cholesterol (data not presented). The absence of associations between size at birth and these factors is consistent with the results of some adult studies [7, 9]. The results do not support the earlier suggestion that small 
size at birth is related to a diminished pancreatic beta-cell mass and reduced insulin secretion $[5,6]-$ or at least suggest that this association does not become apparent during the childhood years.

Possible mechanisms for the influence of birthweight on insulin resistance have recently been reviewed in detail elsewhere [7]. Fetal undernutrition in the second trimester of pregnancy (associated with thinness at birth, and secondary to maternal undernutrition) has been postulated to play a central role $[1,4]$. However, in the present study we failed to find an association between thinness at birth and insulin level. This was not simply a question of statistical power, because the inverse relations between birthweight and insulin level observed in the full data set were also apparent, and statistically significant, in the subjects with birth record data. Although the birth length measurements made under routine conditions are unlikely to be highly precise, they are unlikely to be systematically biased with respect to the other variables measured. Moreover, the strong correlation between length at birth and birthweight, two separately measured variables, in these subjects $(\mathrm{n}=523, \mathrm{r}=0.60)$ supports the overall validity of the length measurements. Our findings are in any case highly consistent with those of earlier studies in children [14-16], which also failed to find any association between thinness at birth and insulin level.

While early life factors appear to influence insulin levels and the development of insulin resistance at the end of the first decade, childhood body build, particularly degree of overweight or obesity, plays a more important role. This finding is not affected by the use of the interquartile range rather than the SD as the unit of comparison. The relative difference is not the result of imprecision of birthweight assessment by maternal recall; the strength of the relationships between birth record birthweight data and insulin are very similar to those obtained using maternal recall. Moreover, although it has been suggested that birthweight is an imprecise marker of later cardiovascular risk when compared with other markers of size at birth [1], none of the other birth size measures studied here is more closely related to insulin level. The strong relation between childhood body build and insulin levels, both fasting and post-load, has been well-documented [25], and is apparent in both the earlier studies examining birthweight-insulin relations in children $[14,15]$. For example, in the study by Law et al. [14], between the bottom and top quarters of the childhood weight distribution there was an increase in fasting insulin of almost $55 \%$, compared with an increase of $5 \%$ between the corresponding quarters of the distribution of birth weight.

'Tracking' of blood glucose metabolism in childhood has been described [26] and it is possible that the relation between birthweight and insulin resistance will be amplified with age (as with the relationship between birthweight and blood pressure $[27,28])$. The observations from a Swedish adult cohort also suggest that the associations may become more pronounced in those who develop the greatest degree of overweight in adult life [7]. However, these possibilities require further substantiation in younger subjects. Studies (particularly longitudinal studies) examining the relative influence of size at birth and current obesity on insulin resistance at different ages in childhood and early adult life, are urgently needed. Moreover, and crucially, the extent to which environmental factors amenable to intervention, perhaps including maternal nutrition [1], underlie the relation between birthweight and insulin resistance needs to be established.

A cknowledgements. This study was supported by the Wellcome Trust (grant no038976/Z/93/Z). M. W. was supported by the British Heart Foundation. We are grateful to: the schools, parents and children who took part in the study; the members of our Research Team (Ms. S. Gassor RGN, Ms. A. Murphy RGN RM, Ms. C. Stuart RGN, Ms. L. Went RGN); Dr. A. Majeed, Dr. I.Perry, J.Poloniecki. Smith, Kline Beecham PLC generously donated supplies of Lucozade for the study. We are particularly grateful to Ms. L. Ashworth, who performed the insulin assays in Newcastle-upon-Tyne. Glucose analyses were performed by the Department of Clinical Biochemistry at St Georgis Hospital Medical School, London (Professor C. Seymour, Dr J. Nistet).

\section{References}

1. Barker DJP (1994) Mothers, babies and disease in later life. British Medical Journal Books, London

2. Barker DJP, Winter PD, Osmond C, Margetts B, Simmonds SJ (1989) Weight in infancy and death from ischaemic heart disease. Lancet II: 577-580

3. Barker DJP, Osmond C, Simmonds SJ, Wield GA (1993) The relation of small head circumference and thinness at birth to death from cardiovascular disease in adult life. BMJ 306: 422-426

4. Barker DJP (1995) Fetal origins of coronary heart disease. BMJ 311: 171-174

5. Hales CN, Barker DJP, Clarke PMS et al. (1991) Fetal and infant growth and impaired glucose tolerance at age 64 years. BMJ 303: 1019-1022

6. Phipps K, Barker DJP, Hales CN, Fall CHD, Osmond C, Clarke PMS (1993) Fetal growth and impaired glucose tolerance in men and women. Diabetologia 36: 225-228

7. Lithell HO, McKeigue PM, Berglund L, Mohsen R, Lithell U-B, Leon DA (1996) Relation of size at birth to non-insulin dependent diabetes and insulin concentrations in men aged 50-60 years. BMJ 312: 406-410

8. Robinson S, Walton RJ, Clarke PMS, Barker DJP, Hales CN, Osmond C (1992) The relation of fetal growth to plasma glucose in young men. Diabetologia 35: 444-446

9. Valdez R, Athens MA, Thompson GH, Bradshaw RS, Stern MP (1994) Birthweight and adult health outcomes in a biethnic population in the USA. Diabetologia 37: 624631

10. McCance DR, Pettitt DJ, Hanson RL, Jacobsson LTH, Knowler WC, Bennett PH (1994) Birth weight and non-insulin dependent diabetes: thrifty genotype, thrifty 
phenotype, or surviving small baby genotype? BMJ 308: 942-945

11. Olah KS (1996) Low maternal birth weight - an association with impaired glucose tolerance in pregnancy. J Obs Gynae 16: 5-8

12. Barker DJP, Hales CN, Fall CHD, Osmond C, Phipps K, Clark PMS (1993) Type 2 (non-insulin-dependent) diabetes mellitus, hypertension and hyperlipidaemia (syndrome $\mathrm{X}$ ): relation to reduced fetal growth. Diabetologia 36: 62-67

13. Phillips DIW, Barker JPD, Hales CN, Hirst S, Osmond C (1994) Thinness at birth and insulin resistance in adult life. Diabetologia 37: 150-154

14. Law CM, Gordon GS, Sheill AW, Barker DJP, Hales CN (1995) Thinness at birth and glucose tolerance in sevenyear-old children. Diabet Med 12: 24-29

15. Yajnik CS, Fall CHD, Vaidya U et al. (1995) Fetal growth and glucose and insulin metabolism in four-year-old Indian children. Diabet Med 12: 330-336

16. Forrester TE, Wilks RJ, Bennett FI et al. (1996) Fetal growth and cardiovascular risk factors in Jamaican children. BMJ 312: 156-160

17. Whincup PH, Cook DG, Adshead FA et al. (1996) Cardiovascular risk factors in British children in towns with widely differing adult cardiovascular mortality rates. BMJ 313: 7984

18. Groop PH, Melander A, Groop LC (1993) The relationship between early insulin release and glucose tolerance in healthy subjects. Scand J Clin Lab Invest 53: 405-409

19. Andersen L, Dinesen B, Jorgensen PN, Poulsen F, Roder ME (1993) Enzyme immunoassay for intact human insulin in serum or plasma. Clin Chem 39: 578-582
20. Matthews DR, Hosker JP, Rudenski AS, Naylor BA, Treacher DF, Turner RC (1985) Homeostasis model assessment: insulin resistance and beta-cell function from fasting plasma glucose and insulin concentrations in man. Diabetologia 28: 412-419

21. Laakso M (1993) How good a marker is insulin level for insulin resistance? Am J Epidemiology 137: 959-965

22. Paneth N, Susser M (1995) Early origin of coronary heart disease (the "Barker hypothesis"). BMJ 310: 411-412

23. Reaven GM (1988) Role of insulin resistance in human disease. Diabetes 37: 1595-1607

24. Taylor S, Whincup PH, Cook DG, Papacosta O, Walker M, Wilson V (1997) Size at birth and blood pressure in 8-11year-old children. BMJ (in press)

25. Freedman DS, Srinivasan SR, Burke GL et al. (1987) Relation of body fat distribution to hyperinsulinaemia in children and adolescents: the Bogalusa Heart Study. Am J Clin Nutr 46: 403-410

26. Spyckerelle Y, Steinmetz J, Deschamps JP (1992) Comparison of measurements of cholesterol, glucose and uric acid taken at 5-year intervals in children and adolescents. Arch Francaises de Pediatrie 49: 875-881

27. Law CM, de Swiet M, Osmond C et al. (1993) Initiation of hypertension in utero and its amplification throughout life. BMJ 306: 24-27

28. Whincup P, Cook DG, Papacosta O, Walker M (1995) Birthweight and blood pressure; cross-sectional and longitudinal relationships in childhood. BMJ 311: 773-776 